\title{
Dual-Energy CT and Spot Sign
}

W

e read with great interest the article published by Morotti et al, "Effect of CTA Tube Current on Spot Sign Detection and Accuracy for Prediction of Intracerebral Hemorrhage Expansion." ${ }^{\prime 1}$ We agree with the authors that the spot sign and also the newly described "leakage sign" 2 represent very useful signs to predict expansion of intracranial hemorrhage of different origins. However, the optimal CT protocol to detect the spot sign is still unknown, and it is not known if new techniques such as dual energy will improve its detection. This is of great importance because the spot sign has changed the way patients with intracranial hemorrhage are managed acutely. It is well known that dual-energy CT increases the sensitivity for the detection of ischemia in pa-
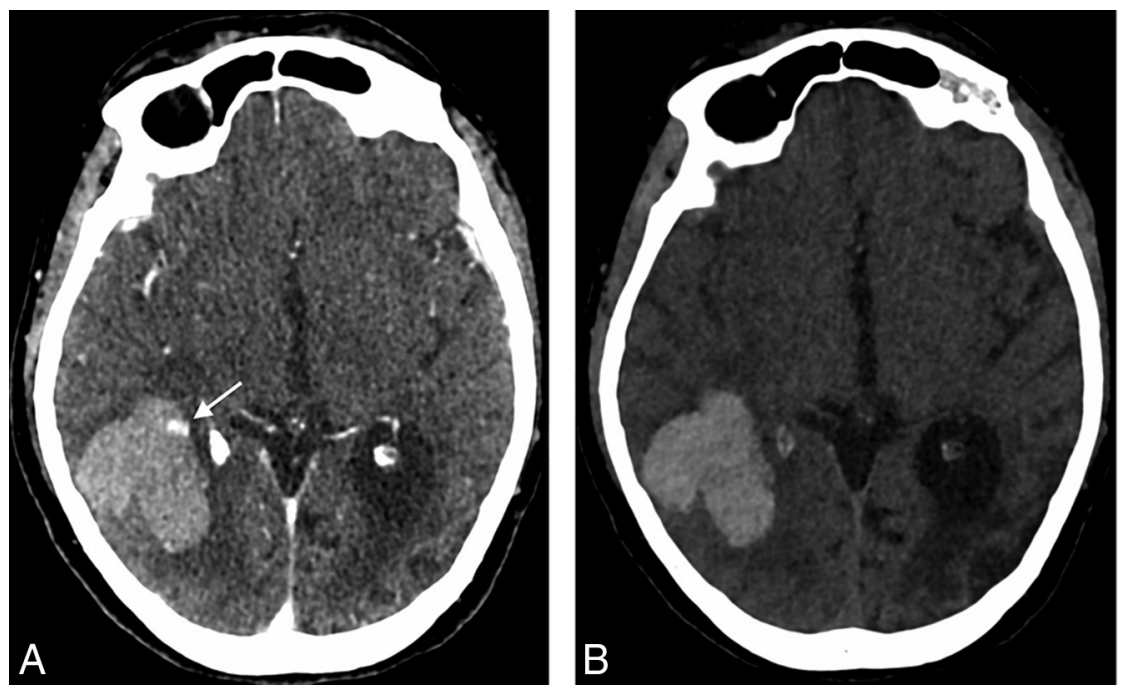

FIG 1. CT $(80 \mathrm{Kv})$ performed with a Siemens machine after contrast agent shows the spot sign in a patient with intracerebral hemorrhage $(A, a r r o w)$. The spot sign disappears on the virtual unenhanced image (B).

tients after mechanical thrombectomy, ${ }^{3}$

and it is also very useful to differentiate between hemorrhage and contrast media. ${ }^{4}$ The question is, what about the spot sign and dual energy?

We have to pay attention to the use of new technologies such as dual-energy CT and these signs because the spot or leakage sign corresponds to leakage of contrast medium, and these might disappear with dual energy in a patient with hemorrhage (Fig 1). Further, the nonvisualization of the spot sign or low sensitivity on CTA (53\%) as described by Orito et $\mathrm{al}^{2}$ might be due to the CTA being done in dual energy.

\section{REFERENCES}

1. Morotti A, Romero JM, Jessel MJ, et al. Effect of CTA tube current on spot sign detection and accuracy for prediction of intracerebral

http://dx.doi.org/10.3174/ajnr.A4894 hemorrhage expansion. AJNR Am J Neuroradiol 2016 May 19. [Epub ahead of print] CrossRef Medline

2. Orito K, Hirohata M, Nakamura $Y$, et al. Leakage sign for primary intracerebral hemorrhage: a novel predictor of hematoma growth. Stroke 2016;47:958-63 CrossRef Medline

3. Gariani J, Cuvinciuc V, Courvoisier D, et al. Diagnosis of acute ischemia using dual energy CT after mechanical thrombectomy. J Neurointerv Surg 2015 Nov 3. [Epub ahead of print] CrossRef Medline

4. Tijssen MP, Hofman PA, Stadler AA, et al. The role of dual energy CT in differentiating between brain haemorrhage and contrast medium after mechanical revascularisation in acute ischaemic stroke. Eur Radiol 2014;24:834-40 CrossRef Medline

(1) M.I. Vargas

(1DK. Lovblad

Division of Neuroradiology Department of Medical Imaging Geneva University Hospital Geneva, Switzerland 